\title{
Auditorias da Qualidade
}

\author{
Alberto W. Ramos \\ Engenheiro de Produção pela Escola Politécnica da Universidade de São Paulo (EPUSP). \\ Professor do Departamento de Engenharia de Produção da EPUSP, na área de métodos \\ quantitativos. Mestrando em Engenharia de Produção pela EPUSP. Engenheiro de \\ Qualidade certificado pela "American Society for Quality Control". Consultor de \\ empresas nas áreas de Controle e Garantia da Qualidade.
}

palavras-chave: Controle da qualidade, Administração da qualidade, Qualidade industrial

Key words: Quality control, Quality management, Industrial quality

\section{RESUMO:}

Este artigo tem como objetivo apresentar os conceitos envolvidos na aplicação de auditorias de qualidade, de forma a ressaltar suas vantagens e desvantagens para toda a organização. É feita uma revisão dos objetivos de uma auditoria de qualidade e das etapas de sua implantação; apontando as principais causas de fracassos na sua aplicação.

\begin{abstract}
:
This paper presents a review of the main concepts in Quality Auditory, highlighting its advantages and disvantages to the organization. The paper also remarks the Auditory objetives and its implementation steps; pointing out the main reasons of unsuccefull cases.
\end{abstract}

Rec. 10/90 Rev. 10/90 Apr. 11/90 


\section{Introdução}

As auditorias da qualidade são uma importante ferramenta para a gestão moderna da qualidade. Embora muitas empresas tenham desenvolvido esta função (algumas até possuem departamentos específicos para a sua execução), ainda não há uma total compreensão das vantagens advindas de sua aplicação.

Este artigo tem por objetivo introduzir os conceitos envolvidos nas auditorias da qualidade, de forma a possibilitar ao leitor um melhor entendimento de suas vantagens para a organização. No final do texto encontramse diversas referências bibliográficas para aqueles que quiserem se aprofundar no assunto.

\section{O Que É Uma}

\section{Auditoria de Qualidade}

Uma auditoria da qualidade é uma avaliação planejada, programada e documentada, executada por pessoal independente da área auditada, a fim de verificar a eficácia do sistema de qualidade implantado, através da constatação de evidências objetivas e da identificação de não-conformidades, servindo como mecanismo de realimentação e aperfeiçoamento do sistema da qualidade (1).

Podemos dizer que esta representa para a função 'qualidade' o que a auditoria contábil representa para a função 'finanças' da empresa. As auditorias contábeis não só verificam a exatidão dos livros, mas também a adequação do sistema contábil. A mesma analogia vale para as audidorias da qualidade (2).

A análise da definição acima fornecida nos permite identificar alguns pontos importantes que merecem destaque: a) A auditoria da qualidade pode ser realizada por qualquer pessoa da organização, desde que:

- esta seja de uma outra área que não a auditada;

- esta esteja treinada e capacitada para a realização da mesma.

b) Uma vez que o objetivo principal da auditoria é verificar a efícácia do sistema da qualidade implantada, consequentemente seu caráter é muito mais de prevenção do que de correção de problemas.

c) Por servir como mecanismo de realimentação, as auditorias são um importante sistema de informações para a administração da empresa, pois possibilitam o aperfeiçoamento da qualidade de seus produtos e serviços.

\section{Tipos de Auditoria}

A literatura existente sobre o assunto costuma apresentar os mais diversos tipos de classificação. Entretanto, podemos basicamente dividi-las em:

\section{Quanto a sua execução:}

- Externas: são aquelas executadas por outras organizações, tais como clientes, empresas especializadas, etc.;

- Internas: são aquelas executadas pela própria organização e costumam ser subdivididas em:

- auditoria de sistemas - examina a eficácia do sistema da qualidade;

- auditoria de processos - avalia a proximidade entre métodos e procedimentos estabelecidos e a prática real; 
- auditoria de itens (produtos e/ou serviços) determina a conformidade de produtos e/ou serviços com as especificaçð̃es técnicas.

\section{Quanto à ocasião de sua realização:}

- pré-contrato ("pre-award") - quando é realizado antes da celebração de um contrato comercial;

- pós-contrato ("post-award") - quando é realizada imediatamente após a celebração do contrato comercial;

- auditoria de projeto-desenvolvimento/préprodução - quando executada nas fases de desenvolvimento do produto/serviço e/ou pré-produção;

- auditoria de produção/construção - quando executada na fase de produção/construção do produto.

\section{Quanto a sua frequência:}

- programação (de rotina) - são aquelas cuja execução está prevista no programa de auditorias;

- não programada (especial) - são aquelas realizadas quando da evidência de problemas ou de deterioração do nível da qualidade.

\section{Objetivos das}

\section{Auditorias da Qualidade}

Os principais objetivos de uma organização para a realização de auditorias da qualidade são:

- Avaliar a conformidade dos procedimentos da qualidade com as normas estabelecidas por clientes ou pela própria empresa;
- Avaliar a aderência dos métodos empregados com os procedimentos estabelecidos;

- Avaliar o processo de tomada de decisão da empresa, com relação à qualidade;

- Avaliar a conformidade das características da qualidade dos produtos/serviços com as especificações;

- Verificar e melhorar a eficácia do sistema da qualidade;

- Detectar problemas potenciais da qualidade de produtos/serviços;

- Permitir à administração uma visão mais profunda da empresa, gerando uma consciência para qualidade.

\section{Implantação de Um Sistema de Auditorias da Qualidade}

Não existe uma fórmula universal (receita de bolo) para a implantação de um sistema de auditorias da qualidade. Cada empresa precisa avaliar especificamente as suas necessidades e, em função destas, desenvolver um esquema que seja compatível com os objetivos estabelecidos.

Entretanto, podemos fazer as seguintes recomendações, que têm se demonstrado eficazes para a implantação do mesmo (3):

O sistema deve ser desenvolvido e administrado por um profissional com experiência na área, tendo o apoio da Alta Administração para a realização deste trabalho;

- O sistema deve ser montado de forma a assegurar que a execução das auditorias seja uma rotina regular dentro da organização; 
- Deve ser selecionado um número determinado de normas, a fim de cobrir convenientemente as exigências da organização (contratuais ou não);

- Todas as auditorias devem ser executadas comparando-se os sistemas da organização contra as exigências das normas escolhidas;

- O sistema deve ser planejado e consistente na sua abordagem;

- Os auditores devem ser treinados em técnicas de auditoria, incluindo-se os aspectos comportamentais;

- O sistema deve ser divulgado, compreendido e aceito por todas as pessoas da organização;

- Deve haver um sistema eficiente de informações da auditoria, com linhas de comunicação bem definidas, uma vez que diversas áreas funcionais estarão envolvidas;

- Deve existir um método eficiente para assegurar que as medidas corretivas sejam implantadas. A auditoria deve ser objetiva, concreta e executada contra uma norma definida da qualidade;

- Um programa de auditorias deve ser delineado e usado com base no sistema de registros de auditoria.

Como resultado do desenvolvimento do sistema de auditorias devemos ter:

a) Um plano de auditorias que defina:

- As áreas funcionais a serem auditadas;

- A designação dos encarregados de efetuar as auditorias;

- A frequência das auditorias;
- O método de relatar eventos e recomendaçōes;

- Os meios para que as ações corretivas sejam determinadas e implementadas.

b) Um conjunto de procedimentos e instruçōes que defina:

- Quem deve fazer a auditoria;

- Quando a auditoria deve ser executada;

- Como a auditoria deve ser executada;

- Onde a auditoria deve ser feita;

- Com que materiais;

- Que registros serão mantidos.

\section{O Plano de}

\section{Auditorias da Qualidade}

O plano de auditorias (fig.1) é um cronograma que, basicamente, estabelece a frequência e responsabilidade pela sua execução.

As informações para o plano das auditorias podem ser obtidas de:

- Relatórios de auditorias anteriores;

- Relatórios de não-conformidades;

- Relatórios de devoluçōes de clientes;

- Relatórios de inspeções;

- Documentação técnica;

- Contratos com clientes.

É importante salientar que a periodicidade das auditorias depende de diversos fatores: 


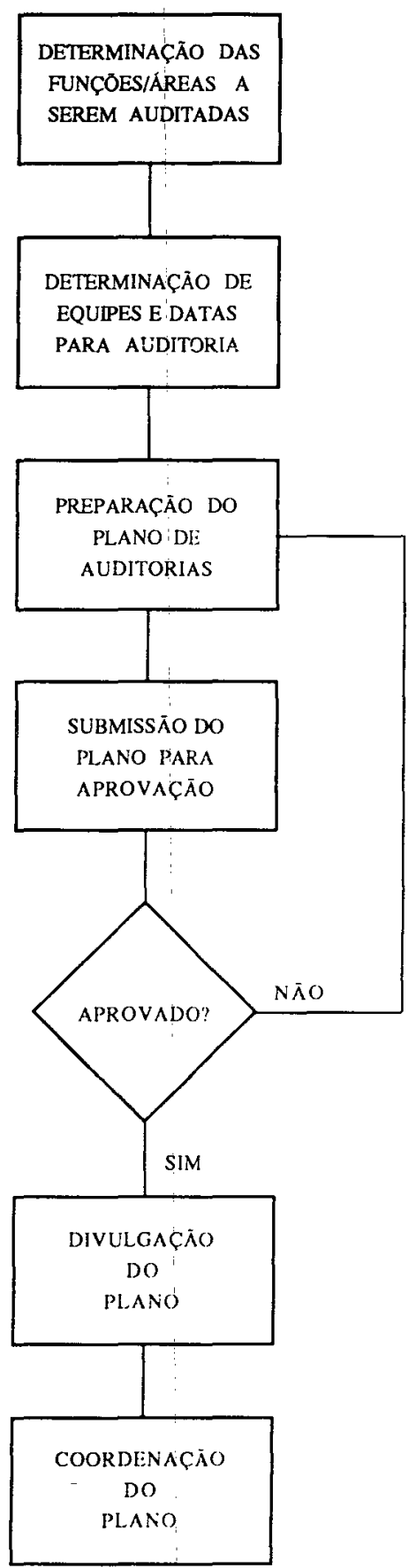

Fig. 1 - Elaboração do Plano de Auditorirs 
número de deficiências encontradas, severidade das deficiências encontradas, custos incorridos devido às deficiências, natureza crítica do item, processo ou função, exigências dos clientes, etc. Entretanto, podemos dizer que a sua frequência deve ser alterada, sempre que da ocorrência de uma das seguintes situaçðes (2):

- Os resultados de auditorias anteriores indicarem a necessidade de efetuá-las com uma maior (ou menor) frequência;

- Quando ocorrerem alterações significativas em áreas funcionais do sistema da qualidade, inclusive reorganizações e revisões de procedimentos;

- Quando a segurança, desempenho ou confiabilidade de um item estiver, ou se suspeitar que esteja, ameaçada devido a nãoconformidades;

- Quando for necessário comprovar que as ações corretivas prescritas foram efetivadas.

\section{Etapas de Uma Auditoria}

Uma vez desenvolvida a sistemática de auditorias da qualidade, passamos à fase posterior, que é a sua implantação. Os diversos autores costumam dividir em um número maior ou menor de etapas as auditorias da qualidade. Uma auditoria da qualidade apresenta as seguintes etapas (fig. 2):

- Seleção e treinamento de auditores - nesta etapa é definida a equipe que irá realizar a auditoria, sendo ministrado treinamento básico e familiarização com detalhes específicos a serem avaliados. Os auditores necessitam ter conhecimento dos princípios e práticas da qualidade, produção, engenharia e suprimentos e, estar familiarizados com as exigências e técnicas envolvidas. Além disto, é desejável que $o$ auditor possua as seguintes características (4):

- interesse e tenacidade na avaliação;

- possuidor de atitude e integridade profissional;

- inquisitivo e analítico;

- honesto;

- diplomático;

- disciplinado;

- bom ouvinte;

- bom planejador;

- bom julgador;

- comunicativo.

- Preparação da auditoria - esta etapa compreende todas as atividades preliminares à execução da auditoria propriamente dita. $\mathrm{O}$ primeiro passo é obter toda a documentação da qualidade e confrontá-la com as exigências dos clientes, determinando se o sistema da qualidade é adequado ou não. Em função desta, devem ser elaboradas as listas de verificação a serem empregadas na obtenção de evidências objetivas;

- Execução da auditoria - esta etapa normalmente se inicia com uma reunião entre a equipe de auditoria e o pessoal da área que será auditada. Sua finalidade básica é expor os objetivos da realização da auditoria. A seguir, a equipe de auditores percorrerá a área, verificando a execução das atividades em conformidade com a documentação da qualidade, obtendo evidências objetivas e apontando os resultados/observações nas listas de verificação. Ao final, deve ser realizada uma nova reunião, aonde serão relatada as principais deficiências observadas e combinadas as ações corretivas a serem implementadas. Os princípios que devem nortear a realização de uma auditoria da qualidade são (5): 


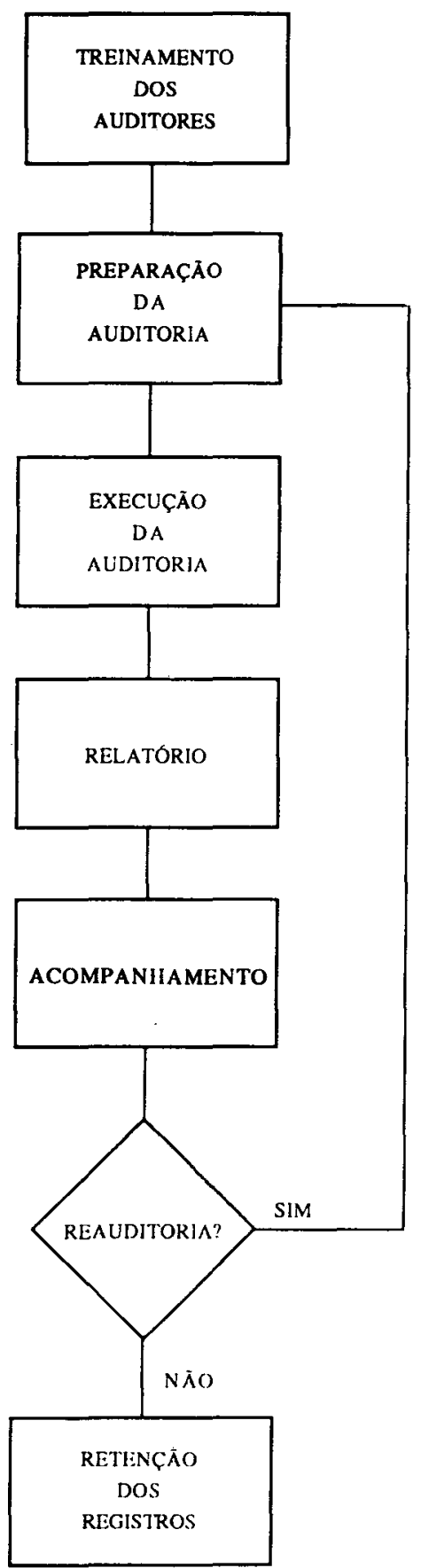

Fig. 2 - Etapas de uma auditoria 
- Para o sucesso de uma auditoria é necessário um amplo conhecimento dos princípios e práticas da qualidade, mas não necessariamente de todos os detalhes do produto/ serviço;

- As técnicas de avaliação devem ser bem assimiladas e praticadas, para garantir a habilitação e competências exigidas para a sua eficácia;

- A auditoria não deve ser feita no escritório do gerente da qualidade, mas sim no local onde são desempenhadas as atividades, através da obtenção de evidências objetivas;

- A auditoria deve se concentrar em itens importantes e não em questões irrelevantes;

- Manter o controle da auditoria, verificando todas as informações recebidas. Verificar se as informações são exatas e completas;

- Não utilizar artifícios de linguagem para amenizar o quadro real. Falar clara e diretamente, dizendo o que deve ser dito;

- Não criticar os resultados antes de discutilos com as pessoas envolvidas. Assegurar que haja uma completa avaliação da situação, antes de considerá-la em desacôrdo;

- Estar de ouvidos sempre abertos, não se deixando estereotipar. Dar crédito aonde deve ser dado;

- Envolver a gerência na crítica, quando a deficiência exigir a sua atenção;

- Acompanhar as ações corretivas, sem perdêlas de vista.

- Relatório da auditoria - a equipe deve preparar um sumário com as deficiências observadas e recomendaçōes, bem como citar as ações corretivas e respectivos prazos de implantação combinados com o pessoal da área auditada. $O$ relatório deve ser emitido tão logo quanto possivel, de moda a formalizar os resultados obtidos na auditoria;

- Acompanhamento - deve ser feito um acompanhamento da ação corretiva 'combinada', prevendo-se, eventualmente, uma reauditoria para verificação de sua efetiva implantação. Ao mesmo tempo deve-se verificar a adequação da ação corretiva 'tomada', ou seja, se esta foi eficaz na resolução do problema e prevenção de sua repetição;

- Retenção de registros - os registros da auditoria (relatórios, listas de verificação, etc.) devem ser arquivados, de forma a serem facilmente recuperados quando necessário.

\section{Por que as auditorias falham}

Embora muitas empresas reconheçam a importância das auditorias como mecanismo de aperfeiçoamento da gestão da qualidade, é comum haver relatos de insucessos ou de sucesso parcial na sua aplicação.

As causas mais comuns deste fracasso são:

- Falta de comprometimento/envolvimento da Alta Administração: Ishikawa (6) ressalta a necessidade do apoio da cúpula da empresa para a eficaz utilização das informaçōes obtidas quando da execução das auditorias da qualidade. Segundo ele, no Japão já se tornou rotina a execução de auditorias pelo próprio presidente da empresa, como forma de garantir bons resultados. Indubitavelmente, todas as ações devem ser implementadas de cima para baixo, para serem bem sucedidas;

- Resistência da organização: se todos na organização não copreenderem a finalidade das auditorias (prevenção, e não deteç̧ão), surgirão focos de resistência, uma vez que as pessoas se sentirão ameaçadas. Portanto, é de 
vital importância a divulgação dos objetivos das auditorias, de preferência, pela Alta Administração;

- Falta de treinamento/habilidade por parte dos auditores: o treinamento ministrado deve não somente enfocar a parte técnica, mas também os aspectos comportamentais envolvidos na auditoria. É surpreendente verificar como muitos auditores se esquecem do ditado: "Môscas se caçam com mel, e não com fel". É muito mais fácil obter as informações em um ambiente cordial e de mútua confiança do que em uma situação de litígio;

- Falha na implantação da ação corretiva: muitas auditorias são bem executadas, e os pontos fracos do sistema da qualidade são levantados, entretanto, não há implantação da ação corretiva necessária à resolução do problema. Isto pode ocorrer devido a dois motivos: falta de acompanhamento (reauditoria) e/ou falta de senso de urgência na sua implantação. Em ambos os casos o ciclo de aperfeiçoamento não se completa e, consequentemente, a empresa não desfruta de seus benefícios.

Muitos outros motivos poderiam ser ainda citados, mas acreditamos que a maior parcela destes se enquadram de alguma forma em uma das categorias acima citadas.

\section{Conclusão}

Conforme dito anteriormente, a finalidade deste artigo não é abordar a questão da auditoria da qualidade em todas as suas minúcias mas, antes de tudo, fornecer uma visão global de um assunto que vem despertando $o$ interesse de profissionais da área. Diversos cursos têm sido ministrados nas principais capitais do país, auxiliando as em- presas na capacitação de seus recursos humanos e facilitando sobremaneira a tarefa de desenvolver e implantar esta importante ferramenta gerencial.

Por fim, gostariamos de lembrar que a auditoria da qualidade é a consequência de um sistema/processo e não o motivo para a existência do mesmo, em outras palavras, é um meio e não um fim para o aperfeiçoamento da qualidade. As informaçðes que são geradas devem ser utilizadas para realimentar o sistema, permitindo que as melhorias sejam obtidas e mantidas a longo prazo.

\section{Bibliogragia}

(1) INSTITUTO BRASILEIRO DO PETRÓLEO. Guias para a implantação de sistemas de garantia da qualidade. Capítulo 1 - Terminologia. 1987.

(2) ASSOCIAÇÃO BRASILEIRA DE NORMAS TÉCNICAS. Coletânea de Normas de Programas de Qualidade, 1986.

(3) PHILIPS: Manual de Qualidade Assegurada.

(4) JOHNSON, L.M. Quality Assurance Program Evaluation. L. Marvin Johnson Associates Inc., 1986.

(5) RIBEIRO DA COSTA, J. Garantia da Qualidade Aplicada aos Ensaios Não Destrutivos. Associação Brasileira de Ensaios Não Destrutivos - ABENDE, 1984.

(6) ISHIKAWA, K. TQC-Total Quality Control. Estratégia e Administração da Qualidade. IM \& C Internacional, 1984. 